

Scand J Work Environ Health 2012;38(6):516-526

https://doi.org/10.5271/sjweh.3293

Published online: 22 Mar 2012, Issue date: 01 Nov 2012

Transitions between sickness absence, work, unemployment, and disability in Denmark 2004-2008

by Pedersen J, Bjorner JB, Burr H, Christensen KB

Affiliation: National Research Center for the Working Environment (NRCWE), Lersø Parkallé 105, DK-2100 Copenhagen Ø, Denmark. jpe@arbejdsmiljoforskning.dk

Refers to the following texts of the Journal: SJWEH Supplements 2009;(7):5-14 SJWEH Supplements 2008;(6):98-110

The following articles refer to this text: 2013;39(2):125-133;

2012;38(6):485-488; 2013;39(2):121-124; 2014;40(4):331-333; 2017;43(5):415-425; 2018;44(2):147-155; 2019;45(3):289-297; 2020;46(6):630-638; 2021;47(7):540-549; 2023;49(1):33-42

Key terms: Denmark; disability; disability pension; methodology; multi-state model; register data; registry; return to work; RTW; sickness absence; unemployment; work

This article in PubMed: www.ncbi.nlm.nih.gov/pubmed/22441355

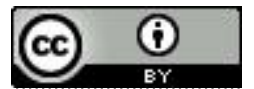




\title{
Transitions between sickness absence, work, unemployment, and disability in Denmark 2004-2008
}

\author{
by Jacob Pedersen, MSc, ${ }^{1}$ Jakob Bue Bjorner, MD, ${ }^{1,2,3}$ Hermann Burr, PhD, ${ }^{4}$ Karl Bang Christensen, PhD ${ }^{2}$
}

Pedersen J, Bjorner JB, Burr H, Christensen KB. Transitions between sickness absence, work, unemployment and disability in Denmark 2004-2008. Scand J Work Environ Health. 2012;38(6):516-526. doi:10.5271/sjweh.3293

\begin{abstract}
Objectives Studies of labor market outcomes like sickness absence are usually restricted to a single outcome. This paper investigates the use of multi-state models for studying multiple transitions between sick-listing, work, unemployment, and disability pension by analyzing longitudinal register data. Every person sick-listed in Denmark during 2004 was followed until the spring of 2008.

Methods A multi-state model was used to analyze transitions between four states: work, sickness absence, unemployment, and disability pension. The first three are possible recurrent states. The predictor variables include age group, gender, geographical region, chronic disease, temporary disease, self-employment sickness absence insurance, and pregnancy. The relative effects of previous transitions were also studied.

Results Risk of transition from sickness absence to disability pension differs with age and geographical region. Those aged 20-29 years have an increased risk of transitioning from work to sickness absence and from sickness absence to unemployment. The self-employed have increased risk of transitioning from work to sickness absence. Those with chronic disease have increased risk of sickness absence, but also a greater probability of returning to work. Previous sickness absence increases the risk of transitioning from work to sickness absence, from sickness absence to unemployment, from work to unemployment, and from work to disability pension.

Conclusions The multi-state model is an effective way of analyzing register data and the transitions between sickness absence, work, unemployment, and disability pension. These methods can be used to develop better predictive models of sickness absence, return to work, unemployment, and disability.
\end{abstract}

Key terms disability pension; methodology; multi-state model; register data; registry; return to work; RTW.

Dwindling labor force participation is a major concern in many countries (1), particularly in Nordic countries that rely on relative high tax rates, and a broad tax base to sustain a high level of welfare. One of the keystones of the Nordic economic model is the flexible labor market (2), which is substantiated by a social security system that acts as a safety net when an employee becomes unemployed, sick-listed, or partly or permanently work disabled. This is often referred to as the "flexicurity model" (3). In the flexicurity model, high labor force participation and continuous adaptability in terms of production is of great importance, due to constant global competition, and there is considerable economic pressure on the social system to help people return to work. To understand the consequences of, and the challenges for, the Danish flexicurity model, it is important to know the boundaries within which it operates. The boundaries are primarily the laws and regulations concerning the model. However, the general understanding of the consequences lies in the flow between different states such as work, unemployment, sickness absence, and disability pension. Transitions from sick-listing to other states are of major social, economic, and political concern due to their direct impact on labor force participation, return to work (RTW), unemployment, and permanent exclu-

1 National Research Centre for the Working Environment, Copenhagen, Denmark.

2 Department of Public Health, University of Copenhagen, Denmark.

3 QualityMetric, Lincoln, RI, USA.

4 Federal Institute for Occupational Safety and Health (BAuA), Berlin, Germany.

Correspondence to: Jacob Pedersen, Statistician, National Research Center for the Working Environment (NRCWE), Lersø Parkallé 105, DK-2100 Copenhagen Ø, Denmark. [E-mail: jpe@arbejdsmiljoforskning.dk] 
sion from the job market. A recent overview of Danish sickness absence focused on sickness absence predictors, RTW following sickness absence, and long-term consequences of sickness absence (4). A total of 17 longitudinal studies combining survey and register data were presented, and predictors of sickness absence and RTW were identified. This new knowledge is largely attributable to the use of the Danish register of social transfer payments (Register for Evaluation of Marginalization - DREAM). The combined use of survey and register data also helps identify those in a working population who are at high risk of subsequent disability pension $(5,6,7)$. However, by using standard methods alone, little can be said about the pathway from work to disability pension, as most people first go through a period of sickness absence.

Analyzing transitions concerning sickness absence presents a methodological challenge $(8,6)$. Follow-ups over time call for the study of several outcomes, eg, "sick-listed", "(returned to) work", "unemployed" or "on disability pension". These outcomes represent different states between which individuals shift. Usually individuals are likely to shift between states several times over time, but in almost all research papers only one of these shifts or transitions is investigated. A larger model that includes all states at the same time is needed to attain a better understanding of transitions between several states, and in particular, how transitions influence later outcomes (7). The present paper uses a multi-state model to describe and analyze transitions in a model containing the four aforementioned states: sick-listed, (returned to) work, unemployed, and on disability pension.

Specifying a model that integrates recurrent events makes it possible to study the effect of previous sickness absence. An analysis of data from the Maastricht Cohort Study on Fatigue at Work found a history of sickness absence to be a significant predictor of future sickness absence among men (9). A cohort study of hospital workers from Minas Gerais, Brazil, also provided evidence that previous sickness absence implies a significant increase in the risk of experiencing new sickness absence (10). Similar results have been found in other studies (11).

The Danish flexicurity system (3) represents a unique blend of a welfare state, with relatively high labor market participation rates, relatively generous and accessible social benefits, a liberal state with relatively low formal employment protection, and a high turnover of the work force between employments. Sickness absence benefits and disability pensions are primarily financed through taxation (3). In 2004, employees had the right to receive sickness absence benefits, or similar compensation, from their municipality if they experienced sickness absence for a given minimum period of $>13$ consecutive days. For the first 13 days, the employer paid sickness absence benefits except for certain groups, eg, people with chronic disease that qualified for a special public insurance. The right to receive a disability pension was granted to Danish residents with limited workability, irrespective of a preceding career on the labor market. Only the unemployment benefit scheme was linked to membership of an insurance fund. In the current study period, approximately $80 \%$ of the work force were members of such unemployment insurance funds. If members of these funds became unemployed, and were available for the labor market, they could receive unemployment benefits. People with no membership in an insurance fund could qualify for social assistance benefits, depending on the total household income. Social payments in Denmark are managed on a regional basis; each region has several local job centers that manage the many individual cases. The overall management is regulated by law, but assessment of individual cases is highly influenced by local policies and regional job market differences.

The present paper uses an extended model for analyzing sickness absence in the context of labor force participation. The paper studies nine transitions between sickness absence, work, unemployment, recurrent sickness absence, and the absorbing state disability pension, in the context of the Danish flexicurity model. The paper uses a multi-state model on longitudinal register data from a cohort of 390060 sick-listed Danish residents taken from the Danish Register of Sickness Absence Compensation and Social Transfer Payments (RSS) (2004-2008) at the National Research Centre for the Working Environment (NRCWE). The use of multi-state models in a large register provides a detailed description of the risk of recurrent events and the transition between the four states, a description currently not available through a standard survival model.

\section{Methods}

\section{Data}

The DREAM register is based on data from the Danish ministries of Employment, Social Affairs and Education. It contains weekly information on social transfer payments for all residents in Denmark (12). In 2008, DREAM contained information on approximately 3.8 million Danes. The RSS register is an extension of DREAM that covers the period from 2004 onwards. The weekly information about sickness absence benefits and maternity allowances are replaced by periods defined by exact dates. Furthermore, all records of sickness absence 
benefits and maternity allowances have been updated with information about region of residence. In addition, periods of sickness absence benefits have been updated with specific information about the type of sick-listing (eg, if pregnancy related or if the person has a chronic disease or is covered by a special employer insurance). A detailed description of the RSS register is available from the NRCWE website (www.arbejdsmiljoforskning. $\mathrm{dk} / \mathrm{da} /$ publikationer/boeger-og-rapporter/boeger-ograpporter?publicationId=636).

\section{Study population}

The study population consists of a cohort of all 390060 Danes (53\% women) aged 20-59 years, who received sickness absence compensation at least once during 2004 , and who had not previously received social benefits concerning disability pension (the period of sickness absence compensation must be active in 2004, but does not necessarily have to start or end in the same year). The persons in the cohort are followed from their first record of sickness absence compensation in 2004 until 26 April 2008.

\section{Covariates}

Ten categorical covariates are used in the analysis: (i) age divided into four groups (20-29, 30-39, 40-49, and 50-59 years); (ii) records of pregnancy starting 36 weeks before the first day of maternity allowance, unless the allowance was associated with adoption; (iii) records of chronic disease insurance compensating the employer from day one when the employee is sick (or used for compensation regarding periodic or continual medical control); (iv) records of special employer insurance for small businesses, compensating the employer from day one if an employee is sick-listed; (v) employment status (self-employed or wage earner); (vi) geographic region (Copenhagen, Sealand, Southern Denmark, Middle Jutland, North Jutland); (vii) number of work periods in the study period (updated throughout study period); (viii) number of unemployment periods in the study period (updated throughout study period); (ix) number of sickness absence periods in the study period (updated throughout study period); and (x) an indicator for long-term sickness absence (LTS) in the period - this covariate changes the first time in the follow-up period a person is registered with a period of sickness absence $>54$ days.

All covariates are time dependent and change during follow-up, eg, when a person shifts from one age group to another. The duration is known for all entering periods of sickness absence, and the covariate LTS includes the entering period. The covariates counting number of periods of work and unemployment do not.

\section{Classification of social benefits}

The analyses present records of transitions between different social benefits by categorizing the transition into four states: sickness absence, work, unemployment, and disability pension. Transitions between these four states are analyzed using multi-state models.

Persons are in the sickness absence state when they receive a sickness absence benefit. The work state contains all time periods when no social benefit payments are registered, (ie, time periods when the person is selfsupporting or working) (13). The unemployment state is when a person is unemployed, but available for the labor market. No differentiation between the two systems of unemployment benefit, unemployment insurance benefit and social assistance benefit is made (13). The state also includes the unemployment benefit for holidays. Persons enter the disability pension state when they receive a disability benefit. This state is considered to be "absorbing" (a state from which further transitions cannot occur) because a disability benefit is granted for the remainder of the person's working life. Persons granted disability pension benefits may still be available for the labor market or be employees, but only on special terms including benefits regarding: national supplementary disability pension (early retirement pension), light job, flexible job, or vacancy benefit for persons with a flexible job.

Persons receiving social benefits that do not fit into these four states are censored (eg, those receiving maternity allowance and social benefits concerning education). Later on if a person receives a social benefit that fits one of the four states, the person reenters the analyses. Furthermore, all persons are censored at the end of the study period, or are censored earlier if they turn 60 years of age, emigrate, or die.

\section{Transitions between states}

The possible transitions between the four states are shown as arrows in the model in figure 1 . The disability pension state has solely arrows running toward it, illustrating that it is an absorbing state.

\section{Multi-state model}

Multi-state models are statistical models that describe the probabilities of transitions between states (14). The simplest multi-state model is a standard survival model with two states: alive and dead. In this model, the observation for an individual is the time until the occurrence of the event "death", described as a transition. Death is an example of an absorbing state, but transient states as well as recurrent events (states that are not absorbing) can also be included. The concept of "censoring", typically by the end of the observation period before all 
individuals under study have died, can also be included in multi-state models.

A multi-state model was used to analyze the transitions between the four states. The nine possible transitions shown in figure 1 were analyzed separately using the Cox proportional hazards model in SAS (PHREG procedure, SAS version 9.2). Data for men and women were analyzed separately.

A model for the occurrence of a transition can be specified using the intensity or hazard function $\lambda(t)$ conditionally on the event history up to time $t$. This function specifies that the risk of a transition in the interval from $t$ to $t+h$ is $\lambda(t) \cdot h$ but only if the person is at risk just before time $t$. The multi-state model is thus defined by nine transitions, one for each of the nine arrows in figure 1: $\lambda_{\mathrm{s}, \mathrm{w}}(t), \lambda_{\mathrm{s}, \mathrm{u}}(t), \lambda_{\mathrm{s}, \mathrm{d}}(t), \lambda_{\mathrm{w}, \mathrm{s}}(t), \lambda_{\mathrm{w}, \mathrm{d}}(t), \lambda_{\mathrm{w}, \mathrm{u}}(t)$, $\lambda_{\mathrm{u}, \mathrm{w}}(t), \lambda_{\mathrm{u}, \mathrm{s}}(t), \lambda_{\mathrm{u}, \mathrm{d}}(t)$. These can be interpreted as the instantaneous probabilities of a specific transition at time $t: \lambda_{\mathrm{h}, \mathrm{j}}(t)=\lambda_{\mathrm{h}, \mathrm{j}, 0}(t) \exp \left(\beta_{1} Z_{1}(t)+\cdots+\beta_{\mathrm{m}} Z_{\mathrm{m}}(t)+\beta_{\mathrm{m}+1} Z_{\mathrm{m}+1}+\cdots+\right.$ $\left.\beta_{\mathrm{k}} Z_{\mathrm{k}}\right)$ in which $h, j \in(\mathrm{S}, \mathrm{W}, \mathrm{U}, \mathrm{D})$ according to figure 1.

The baseline hazard $\lambda_{\mathrm{h}, \mathrm{j}, 0}(t)$ is allowed to vary freely, and the coefficient $\beta$ shows the effect of the covariate $Z$. Note the use of both time-varying covariates $\left(Z(t)_{1 \ldots m}\right)$, such as shift between groups of age range, shifts between the amount of previous unemployment periods, and time constant covariates $\left(Z_{(m+l) \ldots .}\right)$ such as gender (each gender is analyzed separately). The time scale, $t$, used is calendar time.

The major task when using multi-state models is arrangement of the data. The data are arranged such that each line of data consists of one record: an identity variable to keep track of all records that come from the same person, an entry date, and an exit date for every

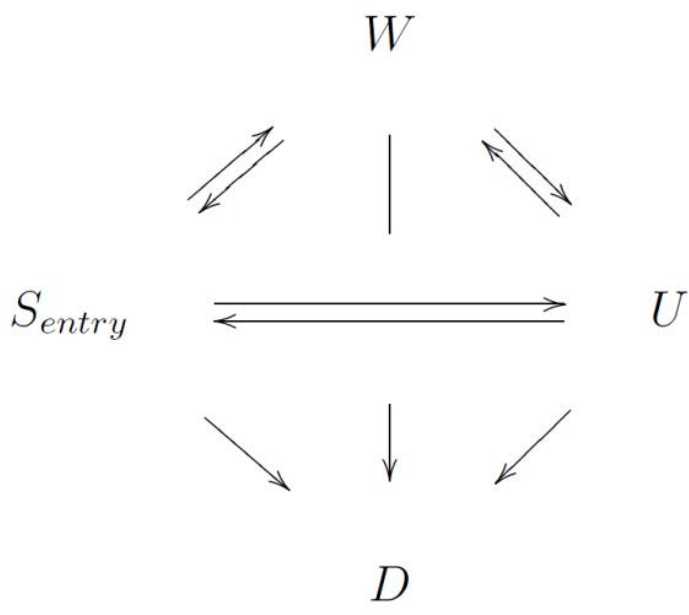

Figure 1. Model for transitions between the four states: working (W), sickness absence (S), unemployment (U) and disability pension (D). The sickness absence state is labeled "entry", to indicate that only sick-listed persons enter the study. record, a status variable for censoring or event type, and the values of the covariates. A record is made for every transition even when censoring, and also whenever a time-varying covariate changes value. Each analysis is controlled for the ten covariates. For each covariate, the assumption of proportionality has been investigated by visual inspection of cumulative hazard curves.

\section{Results}

Table 1 describes the population at the start of follow-up (the entering state). During the four years of follow-up, a total of 1427290 transitions among women and 1495 083 transitions among men were recorded in the RSS register. Table 2 shows the number of persons from the population who experienced each of the nine transitions shown in figure 1 through the entire follow-up. Table 2 does not show recurrent events, which means that only

Table 1. Descriptive table - population at the entering state.

\begin{tabular}{lrrrrr}
\hline & \multicolumn{3}{c}{ Women } & & \multicolumn{2}{c}{ Men } \\
\cline { 2 - 3 } Total & \multicolumn{1}{c}{$\mathrm{N}$} & \multicolumn{1}{c}{$\%$} & & \multicolumn{1}{c}{ N } \\
\cline { 2 - 3 } Copenhagen & 207502 & 53.2 & & 182558 & 46.8 \\
Sealand & 57627 & 27.8 & & 47567 & 26.1 \\
South Denmark & 32246 & 15.5 & & 28628 & 15.7 \\
Mid Jutland & 47350 & 22.8 & & 43394 & 23.8 \\
North Jutland & 47578 & 22.9 & 41685 & 22.8 \\
20-29 years of age & 22701 & 10.9 & & 21284 & 11.7 \\
30-39 years of age & 35830 & 17.3 & & 39264 & 21.5 \\
40-49 years of age & 56355 & 27.2 & 51212 & 28.1 \\
50-59 years of age & 55154 & 26.6 & & 46768 & 25.6 \\
Pregnant, aged 20-39 years & 50539 & 24.4 & 45314 & 24.8 \\
Wage earner & 9624 & 4.6 & & \\
Self-employed & 198019 & 95.4 & & 163542 & 89.6 \\
Common disease & 9483 & 4.6 & 19016 & 10.4 \\
Chronic disease & 167697 & 80.8 & 107269 & 58.8 \\
Special employer insurance & 5160 & 2.5 & 3925 & 2.2 \\
Sickness absence & 34645 & 16.7 & 71364 & 39.1 \\
Long-term sickness absence & 189190 & 91.2 & 169330 & 92.8 \\
& 18312 & 8.8 & 13228 & 7.2 \\
\hline
\end{tabular}

Table 2. The number of persons per transition (no recurrent events). [W=work; $S=$ =sickness absence; $U$ =unemployment; $\mathrm{D}=$ disability pension]

\begin{tabular}{lrrrrr}
\hline & \multicolumn{3}{c}{ Women } & & \multicolumn{2}{c}{ Men } \\
\cline { 2 - 3 } \cline { 5 - 6 } & \multicolumn{1}{c}{$\mathrm{N}$} & $\%$ & & $\mathrm{~N}$ & \multicolumn{1}{c}{$\%$} \\
\cline { 2 - 3 } $\mathrm{S} \rightarrow \mathrm{W}$ & 160816 & 77.5 & & 156262 & 85.6 \\
$\mathrm{~S} \rightarrow \mathrm{U}$ & 58066 & 28.0 & & 37340 & 20.5 \\
$\mathrm{~S} \rightarrow \mathrm{D}$ & 20311 & 9.8 & & 16471 & 9.0 \\
$\mathrm{~W} \rightarrow \mathrm{S}$ & 102558 & 49.4 & & 108585 & 59.5 \\
$\mathrm{~W} \rightarrow \mathrm{U}$ & 84007 & 40.5 & & 66771 & 36.6 \\
$\mathrm{~W} \rightarrow \mathrm{D}$ & 2417 & 1.2 & & 1647 & 0.9 \\
$\mathrm{U} \rightarrow \mathrm{S}$ & 33928 & 16.4 & & 21090 & 11.6 \\
$\mathrm{U} \rightarrow \mathrm{W}$ & 86027 & 41.5 & & 68893 & 37.7 \\
$\mathrm{U} \rightarrow \mathrm{D}$ & 1955 & 0.9 & & 1587 & 0.9
\end{tabular}


the first transition per person is shown. Tables $3 a, 3 b$ and $3 \mathrm{c}$ show the effect of the covariates on the risk of transition for women, and tables $4 \mathrm{a}, 4 \mathrm{~b}, 4 \mathrm{c}$ shows the results for men. Results are shown as hazard ratio (HR) estimates with $95 \%$ confidence intervals $(95 \% \mathrm{CI})$. The nine columns in the tables correspond to the nine possible transitions illustrated in figure 1 .

\section{Transitions from sickness absence to work (RTW)}

A total of $78 \%$ of the women and $86 \%$ of the men experienced this transition during follow-up. Young age, being a wage-earner, chronic disease, and working in a job with a special insurance against sick leave, were strong predictors of RTW. The probability of RTW is higher among those without previous LTS absence or unemployment and those who have previously returned to work. For women, the chance of RTW was highest in Copenhagen, while for men the chance of RTW was lowest in Copenhagen. The chance of RTW was higher if the sick leave was related to pregnancy.

\section{Transitions from sickness absence to unemployment}

This transition includes those losing their job during sickness absence and individuals returning to unemployment after sick-listing. A total of $28 \%$ of the women and $21 \%$ of the men experienced this transition during follow-up. However, this transition only counts for $4-6.5 \%$ of the total transitions. For both genders, risk of unemployment was much lower for the self-employed, persons with previous LTS, and persons who had not previously been unemployed. Women living in regions outside Copenhagen had a higher risk of unemployment, as had pregnant women. Also, women with a special insurance against sick leave had a higher risk of unemployment. For men, risk of unemployment was highest in Copenhagen. Also, men from workplaces with a special insurance had a lower risk of unemployment. For both genders, risk of unemployment was lower for the older employees, employees with chronic disease, and persons with several previous instances of returning to work. The association between unemployment and previous episodes of sickness absence was nonlinear, but the lowest risk of unemployment was for those with one previous episode of sickness absence.

\section{Transitions from sickness absence to disability pension}

Transition from sickness absence to disability pension

Table 3a. Results for women. [HR=hazard ratio; 95\% Cl=95\% confidence interval; LTS=long-term sickness absence]

\begin{tabular}{|c|c|c|c|c|c|c|c|c|c|c|c|c|}
\hline & \multicolumn{4}{|c|}{ Sickness absence $\rightarrow$ Work } & \multicolumn{4}{|c|}{ Sickness absence $\rightarrow$ Unemployment } & \multicolumn{4}{|c|}{ Sickness absence $\rightarrow$ Disability pension } \\
\hline & $\mathrm{N}$ & $\%$ & $\mathrm{HR}$ & $95 \% \mathrm{Cl}$ & $\mathrm{N}$ & $\%$ & $\mathrm{HR}$ & $95 \% \mathrm{Cl}$ & $\mathrm{N}$ & $\%$ & $\mathrm{HR}$ & $95 \% \mathrm{Cl}$ \\
\hline Transition & 344791 & 24.2 & & & 92367 & 6.5 & & & 20400 & 1.4 & & \\
\hline Copenhagen & & & 1.00 & & & & 1.00 & & & & 1.00 & \\
\hline Mid Jutland & & & 0.94 & $0.93-0.94$ & & & 1.03 & $1.01-1.05$ & & & 1.57 & $1.51-1.63$ \\
\hline North Jutland & & & 0.92 & $0.91-0.93$ & & & 1.18 & $1.15-1.21$ & & & 1.35 & $1.28-1.42$ \\
\hline Sealand & & & 0.99 & $0.98-1.00$ & & & 1.06 & $1.04-1.09$ & & & 1.46 & $1.39-1.53$ \\
\hline South Denmark & & & 0.93 & $0.92-0.93$ & & & 1.08 & $1.06-1.10$ & & & 1.70 & $1.63-1.77$ \\
\hline $20-29$ years of age & & & 1.17 & $1.15-1.18$ & & & 1.21 & $1.19-1.24$ & & & 0.83 & $0.78-0.88$ \\
\hline $30-39$ years of age & & & 1.00 & & & & 1.00 & & & & 1.00 & \\
\hline $40-49$ years of age & & & 0.95 & $0.94-0.96$ & & & 0.75 & $0.74-0.76$ & & & 1.09 & $1.05-1.13$ \\
\hline $50-59$ years of age & & & 0.86 & $0.85-0.87$ & & & 0.72 & $0.71-0.74$ & & & 1.51 & $1.46-1.56$ \\
\hline Not pregnant & & & 1.00 & & & & 1.00 & & & & 1.00 & \\
\hline Pregnant & & & 1.43 & $1.40-1.45$ & & & 1.22 & $1.18-1.26$ & & & 0.12 & $0.08-0.18$ \\
\hline Wage earner & & & 1.00 & & & & 1.00 & & & & 1.00 & \\
\hline Self-employed & & & 0.81 & $0.80-0.82$ & & & 0.10 & $0.09-0.12$ & & & 0.75 & $0.68-0.83$ \\
\hline Common disease & & & 1.00 & & & & 1.00 & & & & 1.00 & \\
\hline Chronic disease & & & 4.14 & $4.08-4.20$ & & & 0.52 & $0.47-0.56$ & & & 2.83 & $2.62-3.07$ \\
\hline Special insurance & & & 4.72 & $4.68-4.77$ & & & 1.11 & $1.08-1.14$ & & & 1.08 & $1.00-1.17$ \\
\hline $1 \times$ sickness absence & & & 2.06 & $2.00-2.12$ & & & 1.27 & $1.23-1.32$ & & & 1.78 & $1.65-1.93$ \\
\hline 2×sickness absence & & & 1.00 & & & & 1.00 & & & & 1.00 & \\
\hline$\geq 3 \times$ sickness absence & & & 0.92 & $0.91-0.94$ & & & 1.16 & $1.14-1.18$ & & & 0.92 & $0.87-0.98$ \\
\hline No LTS & & & 1.00 & & & & 1.00 & & & & 1.00 & \\
\hline LTS & & & 0.24 & $0.23-0.24$ & & & 0.34 & $0.33-0.34$ & & & 26.4 & 23.24-30.18 \\
\hline 0xwork & & & 0.33 & $0.32-0.34$ & & & 1.45 & $1.41-1.49$ & & & 1.35 & $1.25-1.45$ \\
\hline $1 \times$ work & & & 1.00 & & & & 1.00 & & & & 1.00 & \\
\hline $2 \times$ work & & & 1.24 & $1.22-1.26$ & & & 0.83 & $0.80-0.85$ & & & 0.81 & $0.75-0.87$ \\
\hline$\geq 3 \times$ work & & & 1.63 & $1.60-1.65$ & & & 0.63 & $0.62-0.65$ & & & 0.68 & $0.63-0.73$ \\
\hline Oxunemployment & & & 1.19 & $1.17-1.21$ & & & 0.15 & $0.14-0.15$ & & & 1.03 & $0.96-1.11$ \\
\hline 1xunemployment & & & 1.00 & & & & 1.00 & & & & 1.00 & \\
\hline 2xunemployment & & & 0.90 & $0.87-0.92$ & & & 1.38 & $1.34-1.42$ & & & 0.93 & $0.85-1.02$ \\
\hline$\geq 3 \times$ unemployment & & & 0.84 & $0.82-0.85$ & & & 2.56 & $2.49-2.62$ & & & 0.77 & $0.71-0.84$ \\
\hline
\end{tabular}


Table 3b. Results women. [HR=hazard ratio; 95\% Cl=95\% confidence interval; LTS=long-term sickness absence]

\begin{tabular}{|c|c|c|c|c|c|c|c|c|c|c|c|c|}
\hline & \multicolumn{4}{|c|}{ Work $\rightarrow$ Sickness absence } & \multicolumn{4}{|c|}{ Work $\rightarrow$ Unemployment } & \multicolumn{4}{|c|}{ Work $\rightarrow$ Disability pension } \\
\hline & $\mathrm{N}$ & $\%$ & $\mathrm{HR}$ & $95 \% \mathrm{Cl}$ & $\mathrm{N}$ & $\%$ & $\mathrm{HR}$ & $95 \% \mathrm{Cl}$ & $\mathrm{N}$ & $\%$ & $\mathrm{HR}$ & $95 \% \mathrm{Cl}$ \\
\hline Transition & 277252 & 19.4 & & & 304022 & 21.3 & & & 2417 & 0.2 & & \\
\hline Copenhagen & & & 1.00 & & & & 1.00 & & & & 1.00 & \\
\hline Mid Jutland & & & 1.00 & $0.99-1.01$ & & & 1.24 & $1.23-1.26$ & & & 1.15 & $1.03-1.29$ \\
\hline North Jutland & & & 0.96 & $0.95-0.98$ & & & 1.45 & $1.43-1.47$ & & & 0.98 & $0.84-1.15$ \\
\hline Sealand & & & 1.03 & $1.02-1.05$ & & & 1.13 & $1.11-1.14$ & & & 1.24 & $1.09-1.40$ \\
\hline South Denmark & & & 0.98 & $0.97-0.99$ & & & 1.24 & $1.23-1.25$ & & & 1.30 & $1.16-1.46$ \\
\hline 20-29 years of age & & & 1.09 & $1.07-1.10$ & & & 0.96 & $0.95-0.97$ & & & 0.53 & $0.42-0.68$ \\
\hline $30-39$ years of age & & & 1.00 & & & & 1.00 & & & & 1.00 & \\
\hline $40-49$ years of age & & & 1.00 & $0.99-1.01$ & & & 0.99 & $0.98-1.00$ & & & 1.41 & $1.24-1.59$ \\
\hline $50-59$ years of age & & & 0.99 & $0.98-1.00$ & & & 1.25 & $1.24-1.26$ & & & 2.52 & $2.24-2.83$ \\
\hline Not pregnant & & & 1.00 & & & & 1.00 & & & & 1.00 & \\
\hline Pregnant & & & 1.34 & $1.32-1.37$ & & & 1.15 & $1.13-1.17$ & & & & \\
\hline Wage earner & & & 1.00 & & & & 1.00 & & & & 1.00 & \\
\hline Self-employed & & & 1.35 & $1.33-1.37$ & & & 0.46 & $0.44-0.48$ & & & 0.64 & $0.47-0.88$ \\
\hline Common disease & & & 1.00 & & & & 1.00 & & & & 1.00 & \\
\hline Chronic disease & & & 4.18 & $4.13-4.23$ & & & 0.56 & $0.54-0.58$ & & & 4.79 & $4.20-5.47$ \\
\hline Special insurance & & & 1.90 & $1.88-1.92$ & & & 0.76 & $0.76-0.77$ & & & 0.45 & $0.37-0.56$ \\
\hline 1×sickness absence & & & 0.60 & $0.59-0.61$ & & & 0.90 & $0.89-0.91$ & & & 0.59 & $0.49-0.70$ \\
\hline $2 \times$ sickness absence & & & 1.00 & & & & 1.00 & & & & 1.00 & \\
\hline$\geq 3 \times$ sickness absenc & & & 1.85 & $1.83-1.88$ & & & 1.10 & $1.08-1.11$ & & & 1.84 & $1.52-2.23$ \\
\hline No LTS & & & 1.00 & & & & 1.00 & & & & 1.00 & \\
\hline LTS & & & 1.09 & $1.08-1.10$ & & & 1.22 & $1.21-1.23$ & & & 6.04 & $5.49-6.64$ \\
\hline \multicolumn{13}{|l|}{ 0xwork } \\
\hline $1 \times$ work & & & 1.00 & & & & 1.00 & & & & 1.00 & \\
\hline 2xwork & & & 1.03 & $1.02-1.05$ & & & 0.92 & $0.91-0.93$ & & & 0.53 & $0.44-0.64$ \\
\hline$\geq 3 \times$ work & & & 1.19 & $1.17-1.21$ & & & 0.82 & $0.81-0.84$ & & & 0.43 & $0.35-0.54$ \\
\hline 0xunemployment & & & 0.88 & $0.86-0.89$ & & & 0.09 & $0.08-0.09$ & & & 0.77 & $0.66-0.90$ \\
\hline 1×unemployment & & & 1.00 & & & & 1.00 & & & & 1.00 & \\
\hline 2xunemployment & & & 1.03 & $1.01-1.05$ & & & 1.49 & $1.47-1.51$ & & & 0.62 & $0.47-0.82$ \\
\hline$\geq 3 \times$ unemployment & & & 1.02 & $1.01-1.04$ & & & 2.68 & $2.65-2.71$ & & & 0.40 & $0.31-0.52$ \\
\hline
\end{tabular}

is the most common of the three transitions to disability pension illustrated in figure 1 . The risk of disability pension is lowest in Copenhagen and increases with age, the gradient being steeper for men than women. The risk is lower for self-employed and higher for those with chronic disease or special insurance. Previous LTS dramatically increased the risk of disability, while for previous sickness absence the results are more mixed. Risk of disability pensioning was much lower for pregnant women.

\section{Transitions from work to sickness absence}

The study population is sick-listed at the beginning of follow-up and this transition thus concerns the risk of another sickness absence episode among those who have returned to work. The risk was higher for the self-employed, persons with chronic disease, and those working in companies with a special sickness absence insurance program. The risk was higher for pregnant women, young women, and those with previous LTS, several previous instances of RTW, or previous instances of unemployment.

\section{Transitions from work to unemployment}

A total of $41 \%$ of the women and $37 \%$ of the men experienced this transition. The risk of unemployment was much lower for the self-employed and people with no or few previous episodes of unemployment. For women, the risk of unemployment was higher for persons living outside Copenhagen and pregnant women. For both genders, risk of unemployment was higher among 50-59-year-olds and people with previous sickness absence or LTS. The risk was lower for persons with chronic disease, special insurance, and previous RTW.

\section{Transitions from work to disability pension}

Direct transition from work to disability pension occurred very rarely. The risk increased with age and was higher for those with chronic disease and previous LTS and sickness absence. The risk was much lower for persons with a special insurance and several previous instances of RTW. The association between previous unemployment and risk of disability pension was nonlinear, the risk being highest for those with one previous episode of unemployment.

\section{Transitions from unemployment to sickness absence}

A total of $16 \%$ of the women and $12 \%$ of the men registered sick during unemployment. Risk of sickness absence was lower for the self-employed and those with 
Table 3c. Results women. [HR=hazard ratio; 95\% Cl=95\% confidence interval; LTS=long-term sickness absence]

\begin{tabular}{|c|c|c|c|c|c|c|c|c|c|c|c|c|}
\hline & \multicolumn{4}{|c|}{ Unemployment $\rightarrow$ Sickness absence } & \multicolumn{4}{|c|}{ Unemployment $\rightarrow$ Work } & \multicolumn{4}{|c|}{ Unemployment $\rightarrow$ Disability pension } \\
\hline & $\mathrm{N}$ & $\%$ & $\mathrm{HR}$ & $95 \% \mathrm{Cl}$ & $\mathrm{N}$ & $\%$ & $\mathrm{HR}$ & $95 \% \mathrm{Cl}$ & $\mathrm{N}$ & $\%$ & $\mathrm{HR}$ & $95 \% \mathrm{Cl}$ \\
\hline Transition & 63744 & 4.5 & & & 320342 & 22.4 & & & 1955 & 0.1 & & \\
\hline Copenhagen & & & 1.00 & & & & 1.00 & & & & 1.00 & \\
\hline Mid Jutland & & & 1.06 & $1.04-1.09$ & & & 1.16 & $1.14-1.17$ & & & 3.82 & $3.28-4.45$ \\
\hline North Jutland & & & 1.02 & $0.99-1.05$ & & & 1.10 & $1.08-1.11$ & & & 3.19 & $2.68-3.81$ \\
\hline Sealand & & & 1.05 & $1.02-1.08$ & & & 1.10 & $1.09-1.12$ & & & 1.90 & $1.57-2.29$ \\
\hline South Denmark & & & 1.05 & $1.03-1.07$ & & & 1.12 & $1.11-1.13$ & & & 2.79 & $2.37-3.27$ \\
\hline $20-29$ years of age & & & 1.01 & $0.99-1.04$ & & & 0.96 & $0.95-0.97$ & & & 0.56 & $0.46-0.68$ \\
\hline $30-39$ years of age & & & 1.00 & & & & 1.00 & & & & 1.00 & \\
\hline $40-49$ years of age & & & 1.02 & $1.00-1.04$ & & & 0.97 & $0.96-0.97$ & & & 1.71 & $1.53-1.91$ \\
\hline $50-59$ years of age & & & 0.93 & $0.91-0.95$ & & & 0.80 & $0.79-0.81$ & & & 1.84 & $1.63-2.08$ \\
\hline Not pregnant & & & 1.00 & & & & 1.00 & & & & 1.00 & \\
\hline Pregnant & & & 1.08 & $1.04-1.13$ & & & 0.96 & $0.94-0.98$ & & & & \\
\hline Wage earner & & & 1.00 & & & & 1.00 & & & & 1.00 & \\
\hline Self-employed & & & 0.77 & $0.68-0.87$ & & & 0.59 & $0.56-0.62$ & & & 0.62 & $0.36-1.04$ \\
\hline Common disease & & & 1.00 & & & & 1.00 & & & & 1.00 & \\
\hline Chronic disease & & & 1.36 & $1.27-1.45$ & & & 0.99 & $0.95-1.02$ & & & 1.89 & $1.33-2.69$ \\
\hline Special insurance & & & 0.90 & $0.87-0.92$ & & & 1.02 & $1.00-1.03$ & & & 1.32 & $1.07-1.63$ \\
\hline 1×sickness absence & & & 0.68 & $0.66-0.69$ & & & 1.18 & $1.17-1.19$ & & & 0.89 & $0.78-1.02$ \\
\hline 2×sickness absence & & & 1.00 & & & & 1.00 & & & & 1.00 & \\
\hline$\geq 3 \times$ sickness absence & & & 1.69 & $1.65-1.72$ & & & 0.87 & $0.86-0.88$ & & & 1.18 & $0.98-1.42$ \\
\hline No LTS & & & 1.00 & & & & 1.00 & & & & 1.00 & \\
\hline LTS & & & 0.84 & $0.83-0.86$ & & & 0.74 & $0.74-0.75$ & & & 7.98 & $6.72-9.47$ \\
\hline 0xwork & & & 1.10 & $1.07-1.13$ & & & 0.38 & $0.37-0.38$ & & & 1.70 & $1.51-1.92$ \\
\hline $1 \times$ work & & & 1.00 & & & & 1.00 & & & & 1.00 & \\
\hline 2xwork & & & 0.93 & $0.90-0.96$ & & & 1.51 & $1.49-1.52$ & & & 0.55 & $0.44-0.67$ \\
\hline$\geq 3 \times$ work & & & 0.97 & $0.95-0.99$ & & & 2.86 & $2.83-2.90$ & & & 0.36 & $0.28-0.44$ \\
\hline 0xunemployment & & & &.. & & & & & & & & \\
\hline 1xunemployment & & & 1.00 & & & & 1.00 & & & & 1.00 & \\
\hline 2xunemployment & & & 1.44 & $1.40-1.47$ & & & 0.99 & $0.98-1.00$ & & & 0.45 & $0.39-0.52$ \\
\hline$\geq 3 \times$ unemployment & & & 1.95 & $1.90-2.00$ & & & 1.03 & $1.02-1.05$ & & & 0.27 & $0.23-0.33$ \\
\hline
\end{tabular}

Table 4a. Results men. [HR=hazard ratio; 95\% Cl=95\% confidence interval; LTS=long-term sickness absence]

\begin{tabular}{|c|c|c|c|c|c|c|c|c|c|c|c|c|}
\hline & \multicolumn{4}{|c|}{ Sickness absence $\rightarrow$ Work } & \multicolumn{4}{|c|}{ Sickness absence $\rightarrow$ Unemployment } & \multicolumn{4}{|c|}{ Sickness absence $\rightarrow$ Disability pension } \\
\hline & $\mathrm{N}$ & $\%$ & $\mathrm{HR}$ & $95 \% \mathrm{Cl}$ & $\mathrm{N}$ & $\%$ & $\mathrm{HR}$ & $95 \% \mathrm{Cl}$ & $\mathrm{N}$ & $\%$ & $\mathrm{HR}$ & $95 \% \mathrm{Cl}$ \\
\hline Transition & 505200 & 33.8 & & & 57451 & 3.8 & & & 16621 & 1.1 & & \\
\hline Copenhagen & & & 1.00 & & & & 1.00 & & & & 1.00 & \\
\hline Mid Jutland & & & 1.05 & $1.04-1.06$ & & & 0.87 & $0.85-0.89$ & & & 1.47 & $1.41-1.54$ \\
\hline North Jutland & & & 1.04 & $1.03-1.05$ & & & 0.97 & $0.95-1.00$ & & & 1.32 & $1.25-1.39$ \\
\hline Sealand & & & 1.06 & $1.05-1.07$ & & & 0.95 & $0.93-0.98$ & & & 1.43 & $1.36-1.51$ \\
\hline South Denmark & & & 1.05 & $1.04-1.06$ & & & 0.96 & $0.94-0.99$ & & & 1.65 & $1.58-1.72$ \\
\hline $20-29$ years of ag & & & 1.13 & $1.12-1.14$ & & & 1.13 & $1.10-1.16$ & & & 0.87 & $0.81-0.93$ \\
\hline $30-39$ years of ag & & & 1.00 & & & & 1.00 & & & & 1.00 & \\
\hline $40-49$ years of ag & & & 0.87 & $0.86-0.88$ & & & 0.80 & $0.78-0.82$ & & & 1.23 & $1.17-1.29$ \\
\hline $50-59$ years of ag & & & 0.75 & $0.74-0.76$ & & & 0.71 & $0.70-0.73$ & & & 1.76 & $1.68-1.83$ \\
\hline Wage earner & & & 1.00 & & & & 1.00 & & & & 1.00 & \\
\hline Self-employed & & & 0.69 & $0.68-0.70$ & & & 0.09 & $0.08-0.11$ & & & 0.69 & $0.64-0.74$ \\
\hline Common disease & & & 1.00 & & & & 1.00 & & & & 1.00 & \\
\hline Chronic disease & & & 4.07 & $4.02-4.12$ & & & 0.66 & $0.61-0.71$ & & & 2.27 & $2.10-2.45$ \\
\hline Special insurance & & & 5.01 & $4.97-5.04$ & & & 0.87 & $0.85-0.89$ & & & 1.06 & $1.00-1.12$ \\
\hline 1×sickness absen & & & 2.47 & $2.39-2.56$ & & & 1.14 & $1.09-1.19$ & & & 1.78 & $1.63-1.95$ \\
\hline 2×sickness absen & & & 1.00 & & & & 1.00 & & & & 1.00 & \\
\hline$\geq 3 \times$ sickness abse & nce & & 0.90 & $0.89-0.92$ & & & 1.24 & $1.21-1.27$ & & & 1.01 & $0.95-1.08$ \\
\hline No LTS & & & 1.00 & & & & 1.00 & & & & 1.00 & \\
\hline LTS & & & 0.23 & $0.23-0.23$ & & & 0.37 & $0.37-0.38$ & & & 32.7 & $28.08-38.19$ \\
\hline 0xwork & & & 0.30 & $0.29-0.31$ & & & 1.56 & $1.51-1.62$ & & & 1.33 & $1.22-1.45$ \\
\hline 1xwork & & & 1.00 & & & & 1.00 & & & & 1.00 & \\
\hline 2xwork & & & 1.26 & $1.24-1.28$ & & & 0.80 & $0.77-0.83$ & & & 0.78 & $0.72-0.84$ \\
\hline$\geq 3 \times$ work & & & 1.64 & $1.62-1.67$ & & & 0.59 & $0.57-0.61$ & & & 0.63 & $0.58-0.68$ \\
\hline 0xunemployment & & & 1.09 & $1.08-1.10$ & & & 0.17 & $0.16-0.17$ & & & 0.96 & $0.90-1.03$ \\
\hline 1xunemployment & & & 1.00 & & & & 1.00 & & & & 1.00 & \\
\hline 2xunemployment & & & 0.93 & $0.92-0.95$ & & & 1.36 & $1.32-1.41$ & & & 0.99 & $0.91-1.08$ \\
\hline$\geq 3 \times$ unemploymen & & & 0.94 & $0.93-0.96$ & & & 2.63 & $2.55-2.72$ & & & 0.85 & $0.78-0.92$ \\
\hline
\end{tabular}


Table 4b. Results men. [HR=hazard ratio; 95\% Cl=95\% confidence interval; LTS=long-term sickness absence]

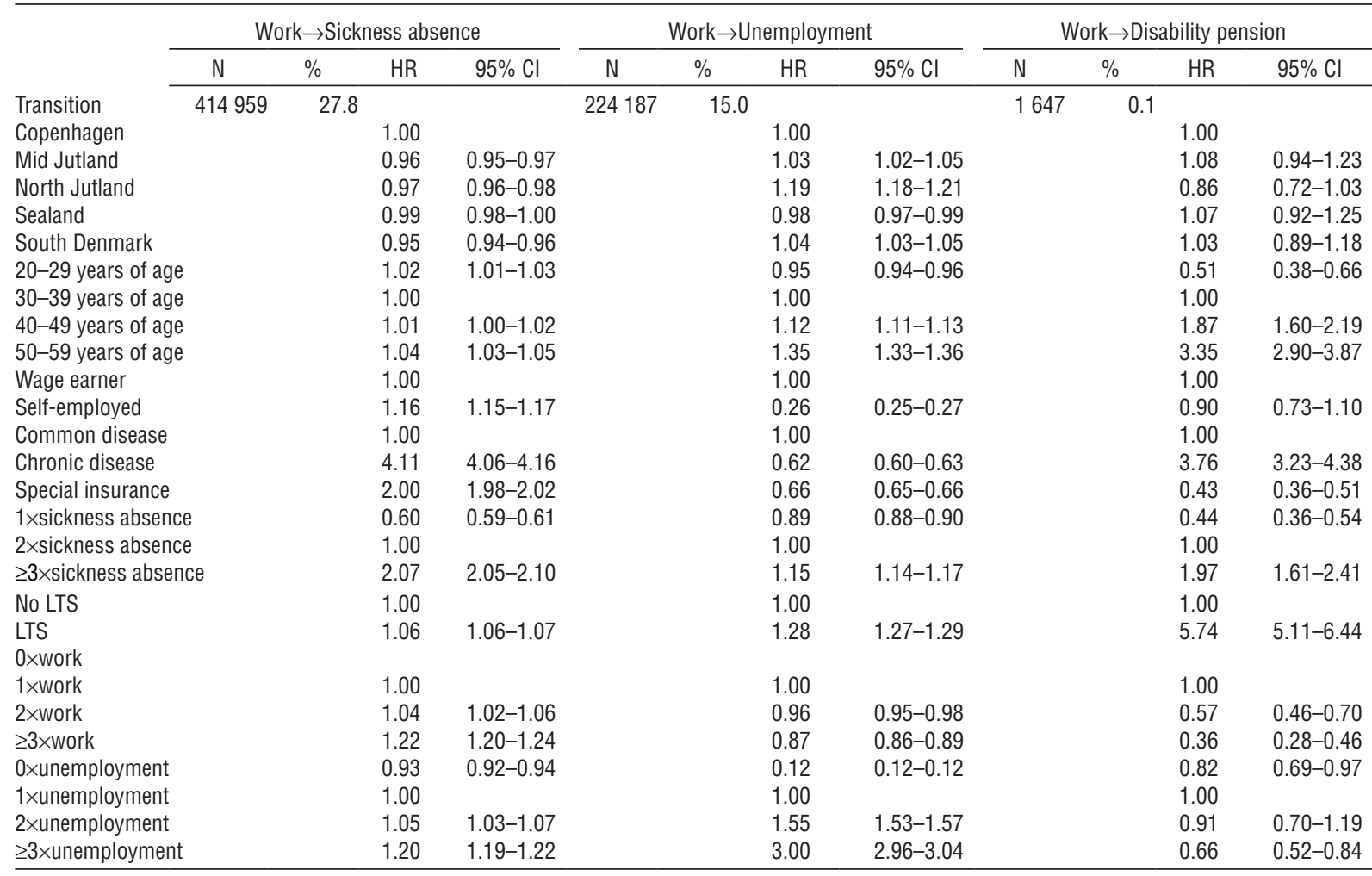

Table 4c. Results men. [HR=hazard ratio; 95\% $\mathrm{Cl}=95 \%$ confidence interval; LTS=long-term sickness absence]

\begin{tabular}{|c|c|c|c|c|c|c|c|c|c|c|c|c|}
\hline & \multicolumn{4}{|c|}{ Unemployment $\rightarrow$ Sickness absence } & \multicolumn{4}{|c|}{ Unemployment $\rightarrow$ Work } & \multicolumn{4}{|c|}{ Unemployment $\rightarrow$ Disability pension } \\
\hline & $\mathrm{N}$ & $\%$ & $\mathrm{HR}$ & $95 \% \mathrm{Cl}$ & $\mathrm{N}$ & $\%$ & $\mathrm{HR}$ & $95 \% \mathrm{Cl}$ & $\mathrm{N}$ & $\%$ & $\mathrm{HR}$ & $95 \% \mathrm{Cl}$ \\
\hline Transition & 36961 & 2.5 & & & 236470 & 15.8 & & & 1587 & 0.1 & & \\
\hline Copenhagen & & & 1.00 & & & & 1.00 & & & & 1.00 & \\
\hline Mid Jutland & & & 1.08 & $1.05-1.11$ & & & 1.37 & $1.35-1.39$ & & & 3.95 & $3.36-4.66$ \\
\hline North Jutland & & & 1.01 & $0.97-1.05$ & & & 1.35 & $1.33-1.37$ & & & 2.95 & $2.43-3.58$ \\
\hline Sealand & & & 1.03 & $1.00-1.07$ & & & 1.23 & $1.21-1.25$ & & & 2.14 & $1.76-2.60$ \\
\hline South Denmark & & & 1.08 & $1.05-1.11$ & & & 1.33 & $1.31-1.35$ & & & 2.99 & $2.52-3.54$ \\
\hline $20-29$ years of age & & & 0.96 & $0.93-0.99$ & & & 1.01 & $1.00-1.02$ & & & 0.65 & $0.53-0.79$ \\
\hline $30-39$ years of age & & & 1.00 & & & & 1.00 & & & & 1.00 & \\
\hline 40-49 years of age & & & 1.07 & $1.04-1.10$ & & & 1.03 & $1.02-1.04$ & & & 1.64 & $1.44-1.87$ \\
\hline $50-59$ years of age & & & 1.06 & $1.04-1.09$ & & & 0.93 & $0.91-0.94$ & & & 1.84 & $1.61-2.10$ \\
\hline Wage earner & & & 1.00 & & & & 1.00 & & & & 1.00 & \\
\hline Self-employed & & & 0.65 & $0.58-0.74$ & & & 0.54 & $0.52-0.57$ & & & 1.02 & $0.75-1.39$ \\
\hline Common disease & & & 1.00 & & & & 1.00 & & & & 1.00 & \\
\hline Chronic disease & & & 1.46 & $1.36-1.56$ & & & 1.15 & $1.12-1.19$ & & & 2.47 & $1.88-3.23$ \\
\hline Special insurance & & & 0.92 & $0.89-0.95$ & & & 1.18 & $1.17-1.19$ & & & 1.23 & $1.04-1.46$ \\
\hline 1×sickness absence & & & 0.65 & $0.63-0.67$ & & & 1.16 & $1.15-1.18$ & & & 0.84 & $0.73-0.96$ \\
\hline 2xsickness absence & & & 1.00 & & & & 1.00 & & & & 1.00 & \\
\hline$\geq 3 \times$ sickness absence & & & 1.76 & $1.71-1.81$ & & & 0.90 & $0.89-0.91$ & & & 1.18 & $0.98-1.41$ \\
\hline No LTS & & & 1.00 & & & & 1.00 & & & & 1.00 & \\
\hline LTS & & & 0.85 & $0.83-0.87$ & & & 0.78 & $0.77-0.79$ & & & 5.35 & $4.51-6.34$ \\
\hline 0xwork & & & 1.29 & $1.25-1.33$ & & & 0.41 & $0.40-0.41$ & & & 1.64 & $1.44-1.86$ \\
\hline 1×work & & & 1.00 & & & & 1.00 & & & & 1.00 & \\
\hline 2xwork & & & 0.93 & $0.89-0.96$ & & & 1.41 & $1.39-1.43$ & & & 0.79 & $0.66-0.95$ \\
\hline$\geq 3 \times$ work & & & 0.97 & $0.94-1.00$ & & & 2.54 & $2.51-2.58$ & & & 0.36 & $0.29-0.45$ \\
\hline \multicolumn{13}{|l|}{ 0xunemployment } \\
\hline 1×unemployment & & & 1.00 & & & & 1.00 & & & & 1.00 & \\
\hline 2xunemployment & & & 1.44 & $1.40-1.49$ & & & 0.99 & $0.98-1.01$ & & & 0.60 & $0.52-0.70$ \\
\hline$\geq 3 \times$ unemployment & & & 2.15 & $2.08-2.22$ & & & 1.14 & $1.13-1.16$ & & & 0.35 & $0.29-0.41$ \\
\hline
\end{tabular}


previous LTS. The risk was higher for those with chronic disease, previous instances of sickness absence, no previous instances of RTW, and more previous episodes of unemployment. Only weak associations with geographic region, age and pregnancy were observed.

\section{Transitions from unemployment to work}

A total of $42 \%$ of the women and $38 \%$ of the men experienced this transition. The chance of transitioning from unmployment to work was much higher for women and men with previous RTW episodes. The probability was higher for men with a chronic disease, special insurance and several previous instances of unemployment [same result found in (13)]. For both men and women, the chance of getting a job was lower among persons living in Copenhagen, 50-59-year-olds, the self-employed, and those with previous LTS.

\section{Transitions from unemployment to disability pension}

This transition was very rare among both men and women. The risk of disability pensioning is higher for persons living outside Copenhagen and those with chronic disease and previous LTS. The risk was lower for those with previous RTW and previous episodes of unemployment. The risk increased with age.

\section{Discussion}

Much of the available knowledge about sickness absences, RTW and long-term consequences of sickness absence in Denmark is based on the DREAM register (4). The present paper uses the RSS register (an extension of the DREAM register) for analyzing transitions between sickness absence, work, unemployment, and disability pension in a cohort of 390060 Danes who were sicklisted during 2004. A unified modeling approach of all transitions was achieved using multi-state models (14).

The Danish Flexicurity model is founded on the flexible labor force and the social welfare system (15). The approach of the present paper determines the efficiency of the Danish flexicurity model in assisting people to return to the labor force after being sick-listed and possibly unemployed. It determines the flexicurity model's ability to include people in the job market that have a chronic disease or are pregnant. Additionally it determines by gender, region, age group etc, how the social welfare system grants disability pension to those who are too disabled to work. Issues that are important for maintaining the Danish model and making the system flexible include both increasing and extending labor force participation.
The geographic region demonstrates the differences between the five regions in Denmark, of which the region of Copenhagen (the capital) is distinguished from the rest. The results show that Copenhagen in particular has a relative high labor force participation, which is unsurprising as Copenhagen has the largest population and the majority of the job market. The flow of the transitions shows that the Copenhagen region has difficulties getting people to return to work and a low probability of granting disability pension. In comparison, the much less populated region of North Jutland has a relatively high probability of allocating disability pension. The differences between regions demonstrate the regional labor force difficulties that Denmark faces, in which younger people in particular, travel to the larger towns to find education and work.

The flow between the states of work, sickness absence, and unemployment confirms the official numbers; most people on sick leave return to work strictly afterwards, a trend that was increasing during 2004-2008 [82.2\% in 2004 and $84.0 \%$ in 2006 (16)]. In addition, less people became unemployed after sick leave $(7.3 \%$ in 2004 and $6.1 \%$ in 2008). The results of the present paper add information to the official numbers: a person with an increasing number of sickness absence periods has an increased risk of becoming unemployed, and the risk of becoming sick again is also increased [also found in $(9,10)]$. If the person becomes unemployed, the probability of RTW is decreased, and the probability of a transition to disability pension is increased when a person returns to work after multiple sickness absence periods.

The additional information confirms the strengths of the multi-state analysis which includes the effect of previous events. The analyses emphasize that the number of previous periods of work, sickness absence, or unemployment influence what future transitions a person is likely to make. This is highly relevant information for the prediction of labor force participation rates and political regulation of the flexicurity model.

Comparing the results for men and woman shows only minor differences (eg, that women have a higher possibility of getting fired if they live in North Jutland). The major differences between men and women are a results of pregnancy, thus pregnant women have a higher risk of sickness absence than their non-pregnant counterparts. In relation to labor force participation, the results on pregnancy emphasize the question of how much one can prevent pregnant workers becoming sick-listed by adapting their work to their current situation (17).

The results on age groups show that young people have a high risk of becoming unemployed after sicklisting, and that people $>40$ years have an increased risk of becoming unemployed and attaining disability pension. The elderly becoming work disabled is probably 
a consequence of a long working life and physical and mental disabilities concerning the working environment. The high probability of unemployment after sickness absence is an example of one of the core elements of the Danish flexicurity model, which entails a relative easy procedure for an employer who wants to lay off a sick-listed employee $(17,2)$.

Three sources of bias are apparent in the presented analysis. Firstly, invisible unemployment occurs in the RSS (ie, an unemployed person not receiving social benefits) (18). Invisible unemployment causes an over estimation of the probabilities concerning the work state and an underestimation of the probabilities concerning the remaining three states. Secondly, when an employee gets laid off during a sickness absence period, the transition from "sick-listed employee" to "sick-listed unemployed person" is not recorded. It is likely that being laid off has an impact on the duration of the sickness absence period and that it decreases the probability of RTW. Thirdly, people in the age range 50-59 years with declining health may choose to wait for early retirement pension instead of applying for disability pension (as suggested in a forecast from the Danish Economic Council) (19). If this is the case, it would cause an over estimation of the probability of sickness absence among the 50-59 year-olds.

Analyzing the flow of the labor force participation by the four-state model has many advantages, compared to more simple approaches $(12,5,20)$. These advantages include: multiple transitions, recurrent events, and exploiting more of the longitudinal information gathered in register data. Despite the advantages of the four-state model, it is still a simplification of the full Danish flexicurity model. The additional knowledge in RSS - particularly about self-employment, chronic disease, and special insurance policies in terms of sickness absence compensation - provides valuable new information about the transitions, especially between the sickness absence and work state (13). The results are very suitable for reflecting on specific regulations, eg, concerning people with chronic disease, and regulations that aim to strengthen their labor force participation.

The results cannot be transferred directly to other countries because of the high influence of Danish laws and regulations concerning the job market and social payments. In addition, the results cannot be generalized to the entire work force, as the analyses only include sick-listed persons, yet the importance of economic coverage when an employee gets sick-listed is explicit. The four-state model could be expanded by adding additional states (eg, an education state) or by differentiating between different types of unemployment benefit (13). This however relies strongly on both the length of the follow-up time and the size of the population analyzed, as all the transitions must take place a minimum number of times to give reliable approximations. The model approach of the present paper follows that of Lie et al (7), but this study's larger sample size permitted the analysis of four states, compared to the three states analyzed by Lie et al (7). The larger sample size makes it possible to determine effects of relative small transitions, eg, from work to disability pension.

The combination of the four-state model and the RSS register analyzed with the multi-state approach have a large potential for further research, eg, the effect of occupational health on the nine transitions. However, since information about region, self-employment, wage earners, chronic disease and special insurance policies only are available when a period of sickness absence are registered in the RSS, any further research that wishes to include such information must incorporate that into the design of the analysis. When analyzing a specific time window, macro-economic cycles influence the results of the model. The period 2004-2008 in Denmark was characterized by a prosperity that enabled an unemployed person to find work. This implies that the results are not necessarily suitable for projections during periods of recession or mixed periods with both recession and prosperity.

Other methods for analyzing multi-state models are available, eg, models based on the Poisson distribution (21). This is appropriate when the baseline hazard is piecewise constant, but, for the data in the RSS, the Cox proportional hazards model was preferred. The use of calendar time as the time axis incorporates the seasonal fluctuation of labor force participation into the baseline hazard.

The results emphasize that sickness absence research can benefit from the use of large datasets, more information on each sick-listing period (geographic region, chronic disease etc), and a larger model that includes more states of transition and the history of prior events.

Interaction between covariates was not analyzed, because the number of covariates available in the RSS would make the risk of type I errors considerable. Furthermore, the data set is very large and this would make many interactions statistically significant. Models with interactions would be suitable for risk prediction, however, this is beyond the scope of the present study.

The results can be combined to yield hazard estimates for different combinations of covariates. The results are particularly suitable for individual risk assessments regarding RTW, recurrent sickness absence or labor market exclusion in terms of unemployment or disability pension. The results are also suitable for optimizing a focused intervention and for political and scientific use. 


\section{References}

1. Dahl E. Disability and employment: sustainability of 'the Nordic model' Eur J Public Health. 2010;20(4):370-1. http:// dx.doi.org/10.1093/eurpub/ckq056.

2. Ferrie JE, Westerlund H, Virtanen M, Vahtera J, Kivimäki M. Flexible labor markets and employee health. Scand SJWEH Supplements 2008;(no 6):98-110.

3. Madsen PK. How can it possibly fly?: The paradox of a dynamic labor market in a Scandinavian welfare state. CARMA Research Papers; 2. CARMA: Aalborg Universitet. 2005;38.

4. Lund T, Labriola M. Sickness absence in Denmark-research, results, and reflections. SJWEH Supplements 2009; (no 7):5-14.

5. Labriola M, Feveile H, Christensen KB, Strøyer J, Lund T. The impact of ergonomic work environment exposures on the probability of disability pension: Prospective results from DWECS/DREAM. Ergonomics. 2009;52:1419-22. http:// dx.doi.org/10.1080/00140130903067771.

6. Christensen KB, Andersen PK, Smith-Hansen L, Nielsen ML, Kristensen TS. Analyzing sickness absence with statistical models for survival data. Scand J Work Environ Health. 2007;33:233-9. http://dx.doi.org/10.5271/sjweh.1132.

7. Lie SA, Eriksen HR, Ursin H, Hagen EM. A multi-state model for sick-leave data applied to a randomized control trial study of low back pain. Scand J Pub Health. 2008;36:279-83. http:// dx.doi.org/10.1177/1403494807086979.

8. Hensing G, Alexanderson K, Allebeck P, Bjurulf P. How to measure sickness absence? Literature review and suggestion of five basic measures. Scand J Soc Med. 1998;26:133-44.

9. Duijts SF, Kant IJ, Landeweerd JA, Swaen GM. Prediction of sickness absence: development of a screening instrument. Occup Environ Med. 2006;63:564-9. http://dx.doi. org/10.1136/oem.2005.024521.

10. Reis RJ, Utzet M, La Rocca PF, Nedel FB, Martin M, Navarro A. Previous sick leaves as predictor of subsequent ones. Int Arch Occup Environ Health. 2011;84:491-9. http://dx.doi. org/10.1007/s00420-011-0620-0.

11. Koopmans PC, Roelen CAM, Groothoff JW. Frequent and long-term absence as a risk factor for work disability and job termination among employees in the private sector. OEM. 2008;65:494-9. http://dx.doi.org/10.1136/oem.2007.034322.
12. Hjollund NH, Larsen FB, Andersen JH. Register-based followup of social benefits and other transfer payments: accuracy and degree of completeness in a Danish interdepartmental administrative database compared with a population-based survey. Scand J Pub Health. 2007;35:497-502. http://dx.doi. org/10.1080/14034940701271882.

13. Rosholm M, Staghøj J, Michael S, Hammer B. A Danish Profiling System. National economic magazine. 2006;144:209 29.

14. Andersen PK, Keiding N. Multi-state models for event history analysis. Statistical Methods Med Res. 2002;11:91-115. http:// dx.doi.org/10.1191/0962280202SM276ra.

15. Danish Ministry of Employment. Flexicurity - Udfordringer for den danske model [Flexicurity - Challenges for the Danish model]. 2005;1:9-13. Available from: http://bm.dk/ Aktuelt/Publikationer/Arkiv/2005/06/ /media/BEM/Files/ Dokumenter/Publikationer/2005/Flexicurity_juni_2005. ashx. Accessed 29/2-2012.

16. Danish Ministry of Employment. Analyse af sygefraværet [Analysis of the sickness absence]. April 2008; Available from: http://www.bm.dk/Aktuelt/Publikationer/Arkiv/2008/04/ Analyse\%20af\%20sygefravaeret.aspx. Accessed 29/2-2012.

17. Lund T, Jensen C, Nielsen ML, Borg V. Sygefravær i et arbejdsmiljøperspektiv. [Sickness absence in a work environment perspective]. May 2003; Available from: http:// www.arbejdsmiljoforskning.dk/ /media/Ubekendte/ sygefravaer.pdf. Accessed 29/2-2012

18. Bjørsted E, Breck J. Faldet i arbejdsstyrken skyldes primært usynlige arbejdsløse. [The decline in the labor force is primarily due to invisible unemployment]. The Economic Council of the Labor Movement, Copenhagen. 2010; Available from: http://www.ae.dk/files/AE faldet-i-arbejdsstyrkenskyldes-primaert-usynlige-arbejdslose.pdf Accessed 29/22012.

19. Danish Economic Council. Efterløn [Early retirement]. Dansk Økonomi. 2005;5.

20. Christensen KB, Feveile H, Labriola M, Lund T. The impact of psychosocial work environment factors on the probability of disability pension in Denmark. Eur J Pub Health. 2008;18:235-7. http://dx.doi.org/10.1093/eurpub/ckm130.

21. Mitnitski AB, Fallah N, Dean CB, Rockwood K. A multi-state model for the analysis of changes in cognitive scores over a fixed time interval. Stat Methods Med Res. 2011 Sep 20. [Epub ahead of print]

Received for publication: 10 October 2011 